\title{
Effect of advanced glycation end products on oxidative stress in endothelial cells in culture: a warning on the use of cells studied in serum-free media
}

\author{
Y. Y.Hui ${ }^{1}$, W.C.McAmis ${ }^{1}$, J.W. Baynes ${ }^{2}$, R.C.Schaeffer ${ }^{3,4}{ }^{4}$ r., M. B. Wolf ${ }^{1}$ \\ ${ }^{1}$ Department of Pharmacology and Physiology, University of South Carolina School of Medicine, Columbia, South Carolina, USA \\ ${ }^{2}$ Departments of Chemistry and Biochemistry, University of South Carolina, Columbia, South Carolina, USA \\ ${ }^{3}$ Sidney Kimmel Cancer Center, San Diego, California, USA \\ ${ }^{4}$ B.W. Zweifach Microcirculation Laboratories, Tucson, Arizona, USA
}

\section{Abstract}

Aims/hypothesis. Alterations in vascular permeability and oxidative stress are characteristics of endothelial dysfunction in diabetic vascular disease. Since AGE-proteins have been hypothesized to mediate these effects, we studied the effects of AGE-bovine serum albumin on endothelial monolayer permeability and intracellular glutathione.

Methods. AGE-BSA was prepared by incubating BSA for 30 days at $37^{\circ} \mathrm{C}$ with $0.5 \mathrm{~mol} / 1$ glucose and $0.2 \mathrm{~mol} / \mathrm{l}$ phosphate buffer, $\mathrm{pH}$ 7.4. Permeability to fluorescently labelled BSA was assessed in a bovine pulmonary artery endothelial cell monolayer preparation. Glutathione was measured by an enzymatic assay.

Results. AGE-BSA concentrations greater than 3 to $4 \mu \mathrm{mol} / \mathrm{l}$ produced maximal increases in permeability (6-8 times basal) within 3 to $4 \mathrm{~h}$ of incubation with the cells. This effect persisted for at least $48 \mathrm{~h}$. However, BSA incubated in the absence of glucose produced similar effects. Dialysis of the AGE-BSA showed that low molecular weight components con- tained the permeability-increasing activity. Phosphate buffer used to prepare the AGE-BSA, at concentrations equivalent to those present in phosphate-buffered saline and in the AGE preparation $(\sim 5 \mathrm{mmol} / \mathrm{l})$, produced similar permeability increases at equivalent incubation times. Metal chelators $(0.5 \mathrm{mmol} / \mathrm{l})$ or inclusion of fetal bovine serum (10-20\%) blocked these permeability increases. These increases in permeability were associated with a decrease in endothelial glutathione, both inhibited by $10 \mathrm{mmol} / \mathrm{l} \mathrm{N}$-acetylcysteine, and a loss of cell-tocell and cell-to-matrix adhesion molecules.

Conclusion/interpretation. Trace amounts of redoxactive metal ions in biological buffers could induce oxidative stress and alterations in cellular functions attributed to AGE-proteins in vitro. It is important to use metal-free phosphate and bicarbonate buffers in studies on cell biology in vitro, especially in serum-free media. [Diabetologia (2001) 44: 1310-1317]

Keywords Advanced glycation end products, endothelial permeability, glutathione, oxidative stress, endothelial monolayers, metal ions.
Received: 8 March 2001 and in revised form: 31 May 2001

Corresponding author: M. B. Wolf, Department of Pharmacology and Physiology, University of South Carolina School of Medicine, Columbia, SC 29208, USA

e-mail: wolf@med.sc.edu

Abbreviations: AGE, Advanced glycatin end products; BPAEC, Bovine pulmonary artery endothelial cell; BSO, buthionine sulfoximine; CML, $\quad \mathrm{N}^{\varepsilon}$-(carboxymethyl)lysine; DTPA, diethylenetriaminepentaacetic acid; FITC, fluorescein isothiocyanate; FL, fructoselysine; GSH, reduced glutathione; EMEM, Eagle's minimum essential medium; NAC, $N$-acetylcysteine; NG-BSA, BSA incubated in the absence of glucose; RAGE, receptor for AGE; ROS, reactive oxygen species; TW, transwell
A common cardiovascular complication of diabetes is an increase in the vascular escape rate of albumin, generally interpreted as an increase in microvascular permeability [1-3]. One of the more recent theories to explain this endothelial dysfunction focuses on the accumulation in blood and tissues of the advanced glycation end products (AGEs) formed from protein modification by glucose [4]. The AGE hypothesis holds that chronic diabetes-accelerated chemical modification of proteins, lipids and other molecules by reducing sugars alters their structure and function, inducing cellular 
damage and a resultant cardiovascular pathology [5].

Advanced glycation end products act on various cell types, including endothelial cells and macrophages, by binding to cell surface receptors, including the scavenger receptor [6] and RAGE (receptor for AGE), [7]. AGE-receptor ligation stimulates these cells to produce reactive oxygen species (ROS) which cause oxidative stress and subsequent endothelial dysfunction. Thus, AGEs are implicated in the transmission of oxidative stress to receptor-bearing cells in the vascular wall [5] and are proposed to be involved in the pathogenesis of the endothelial dysfunction found in diabetes $[8,9]$.

In vivo, inhibition of binding of AGEs to RAGE decreased albumin extravasation from the circulation of diabetic rats [10]. In vitro, it was also shown that AGE-BSA caused cytoskeletal rearrangement and increased inulin permeability in a bovine aortic endothelial monolayer preparation [11]. However, the actual AGEs mediating these responses have not been identified, although one recent, but unconfirmed, report [12] suggests that $\mathrm{N}^{\varepsilon}$-(carboxymethyl)lysine (CML) could be a ligand for RAGE.

One limitation of many in vitro studies on AGEproteins is that there is no standard method of preparing them and quantitating their chemical composition. In various studies, BSA has been incubated for widely varying lengths of time (weeks to many months) with high concentrations of glucose or glucose-6-phosphate at various phosphate buffer concentrations. Before use, the resulting mixture is often dialysed against a variety of solutions, including phosphate-buffered saline. The result is that the composition of the final AGE-protein used is largely unknown or not specified.

Our initial goal was to identify specific AGE molecules involved in the induction of endothelial barrier dysfunction. Our first step was to verify that our preparation of AGE-protein could cause an increase in monolayer permeability to fluorescently-labelled albumin. In the process, we tested a control AGE-protein preparation wherein bovine serum albumin (BSA, endotoxin and fatty-acid free) was incubated in the absence of glucose. Unexpectedly, we found that the control protein, incubated without glucose, was as effective as the AGE-BSA incubated with glucose in induction of monolayer hyperpermeability. This result suggested that some other component(s) of the mixture placed on the cells could be responsible for the alteration in permeability. We conclude that metal-ion impurities in reagent-grade phosphate buffers is the primary factor in induction of barrier dysfunction in monolayers of bovine pulmonary artery endothelial cells (BPAECs). We suggest that the mechanism involves an oxidative stress characterized by a lowering of intracellular glutathione concentration and a loss of cell-to-cell and cell-to-matrix adhe- sion molecules. Because buffer contaminants are a source of oxidative stress, our results suggest caution in the interpretation of experiments using glucose, AGE-proteins and other probes in serum-free media.

\section{Subjects and methods}

All chemicals were obtained from Sigma Chemical, St Louis, Mo., USA unless otherwise indicated.

AGE-protein preparation and characterization. All solutions were passed through an endotoxin-binding column (Detoxigel, Pierce, Rockford, Ill., USA). BSA (10 mg/ml, low-endotoxin, fatty-acid free) was incubated with $0.5 \mathrm{~mol} / \mathrm{l}$ glucose in a $0.2 \mathrm{~mol} / 1 \mathrm{phosphate}$ buffer, $\mathrm{pH} 7.4$, for 30 days at $37^{\circ} \mathrm{C}$, under air. The phosphate buffer provided traces of heavy metal $\left(\mathrm{Fe}^{++}, \mathrm{Cu}^{++}\right.$, etc. $)$to catalyse AGE formation from glucose. This AGE-BSA contained both Amadori compounds and glycoxidation products, including fructoselysine (FL) by chemical analysis at $72 \mathrm{mmol} \mathrm{FL} / \mathrm{mol} \mathrm{Lys,} \mathrm{CML} \mathrm{at} 60 \mathrm{mmol} \mathrm{CML} / \mathrm{mol}$ Lys and pentosidine at $80 \mu \mathrm{mol}$ pentosidine/mol Lys in BSA. Identical results were obtained with other batches of AGEBSA prepared in the same way, but not analysed in detail. The same procedure, but without glucose, was used to prepare a control protein to correct for any denaturation, proteolysis or other modification to BSA which might occur during the incubation, independent of the action of glucose. Aliquots of these reaction mixtures were diluted approximately 40 -fold into Eagle's minimal essential medium (EMEM) for studies of effects on monolayer permeability.

Phosphate buffer preparation and metal-ion chelation. Phosphate buffer stock $(0.2 \mathrm{~mol} / \mathrm{l})$ was prepared by mixing $\mathrm{NaH}_{2}$ $\mathrm{PO}_{4}$ (Fisher Sci., S-369-1) and $\mathrm{Na}_{2} \mathrm{HPO}_{4}$ (Fisher Sci., S393-3) solutions to achieve $\mathrm{pH} 7.4$ using water obtained from a Barnstead Nanopure II water purification system. When the buffer was used in experiments where the effects of divalent metal ion contamination were assessed, the buffer was treated with Chelex-100 resin (10 g wet weight / 101 buffer; Chelex was pre-washed in deionized water to remove fine particles and soluble chelator) [13], in acid-washed (1\% nitric acid) plastic (Nalgene, Nalge-Nunc International, Rochester, NY, USA) bottles for $24 \mathrm{~h}$ at room temperature with gentle rocking. The treated buffer was decanted and stored at $4{ }^{\circ} \mathrm{C}$ in acid-washed plastic bottles. The removal of redox-active metal ions was confirmed by measuring the stability of ascorbic acid in the buffer system [14]. In non-treated $0.2 \mathrm{~mol} / 1$ phosphate buffer, the half-life of ascorbic acid was less than $5 \mathrm{~min}$, whereas in Chelex-treated buffer there was only an approximately $5 \%$ loss in $1 \mathrm{~h}$. Adding about $500 \mathrm{nmol} / \mathrm{l} \mathrm{Cu}^{++}$to the treated buffer increased the rate of ascorbate oxidation to that of the untreated buffer.

Cell culture. BPAECs at passage 6 were obtained from R.C. Schaeffer, Jr. at the Sidney Kimmel Cancer Center, San Diego, Calif., USA [15]. They were used from passages 7-13. The cells were grown to confluence in T-75 flasks, detached by exposure to $0.1 \%$ trypsin (Worthington, Worthington Biochemical, Lakewood, NJ, USA)-EDTA solution and then seeded on $100 \mu \mathrm{g} / \mathrm{ml}$ gelatin- and $25 \mu \mathrm{g} / \mathrm{ml}$ fibronectin-coated CorningCostar transwell (TW) filters $\left(200 \mathrm{~nm}\right.$ radius pores, $0.33 \mathrm{~cm}^{2}$ surface area) (Corning, Corning, NY, USA) at a subconfluent cell density of 75000 cells per well [15]. Monolayers were grown in a medium consisting of DMEM (Cellgro, Mediatech, Herndon, VA, USA) with $10 \%$ fetal bovine serum (FBS, At- 
lanta Biological, Atlanta, Ga., USA), $100 \mathrm{U} / \mathrm{ml}$ penicillin, $100 \mu \mathrm{g} / \mathrm{ml}$ streptomycin, and $2 \mu \mathrm{g} / \mathrm{ml}$ fungizone. Confluent cell monolayers were obtained 3 to 5 days after seeding.

Permeability measurements. Monolayer barrier function to BSA was assessed by adding $100 \mu \mathrm{l}$ EMEM, containing $15 \mathrm{mmol} / \mathrm{l}$ (N-[2-hydroxyethyl]piperazine-N'-[2-ethanesulfonic acid]), HEPES, and fluorescently-labelled BSA, to the top well of each of 12 TWs and $600 \mu l$ of the HEPES-EMEM to the corresponding 12 bottom wells in another 24-well plate. The BSA was labelled with FITC [16]. At time zero, the top wells were rapidly transferred to the other plate's bottom wells. At $1.5-3 \mathrm{~h}$, the transport was stopped by rapidly transferring the top wells back to the original plate. The volumes used avoided any convective transport [15] due to hydrostatic pressure gradients between the two wells. Aliquots $(30 \mu \mathrm{l})$ of the solution in each top well were pipetted into another 24-well plate and $570 \mu \mathrm{l}$ of the HEPES-EMEM added to each of the 12 wells to total $600 \mu \mathrm{l}$. Fluorescence in the 24 -well plates was measured (excitation at $485 \mathrm{~nm}$; emission at $535 \mathrm{~nm}$ ) in a Tecan SPECTRAfluor microplate reader. BSA diffusional permeability was calculated from the ratio of the measured fluorescence concentrations in the top and bottom wells [17].

Glutathione Determination. Total intracellular glutathione, predominantly reduced glutathione (GSH), was assessed on endothelial monolayers incubated with HEPES-EMEM in $100 \mathrm{~mm}$ dishes using an enzymatic recycling method [18].

Labelling of cytoskeletal structures and digital imaging. BPAECs were treated, stained and imaged as described previously [19]. Primary monoclonal antibodies to $\alpha$-catenin (1:100 dilution, Zymed Laboratories, San Francisco, Calif., USA) were used to detect the adherens junctions and mouse antipaxillin IgG (1:200 dilution, Chemicon, Temecula, Calif., USA) was used to detect focal adhesions. After washing, secondary goat TRITC or Cy5-labelled anti-rabbit IgG (1:25 dilution) and goat-Cy5 anti-mouse IgG (1:25 dilution; Jackson Immunoresearch Labs, Westgrove, Pa., USA) were used to label each primary IgG. Alexa 488-phalloidin (Molecular Probes, Eugene, Ore., USA) was used to label F-actin. The digital imaging microscopic workstation used to view the stained slides was a Nikon E-800 microscope with a $60 \mathrm{X}, 1.4$ NA oil immersion objective. A Perkin Elmer Wallac UltraVIEW confocal scanner with a $50 \mathrm{~mW}$ Krypton/Argon three-line laser were used to simultaneously collect Alexa 488, tetramethylrhodamine (TRITC) or Cy5 staining pattern for each sample.

Statistics and data analysis. Data given in the text are means \pm SEM. Statistical significance of changes in each group was assessed from a one-way analysis of variance (ANOVA) using a Student Newman-Keuls post-test to account for multiple comparisons [20]. Paired comparisons were made when appropriate. Significance was accepted at a $p$ value of less than 0.05 . All statistical comparisons were with the InStat computer program (GraphPad, San Diego, Calif., USA). Sigmoidal curve fits to the dose-response data were generated with the SigmaPlot program (SPSS, Chicago, Ill., USA).

\section{Results}

Permeability: Time-dose-response relations for AGE$B S A$. The effects of $48 \mathrm{~h}$ of AGE-BSA incubation on permeability are shown in Figure 1 . The concen-

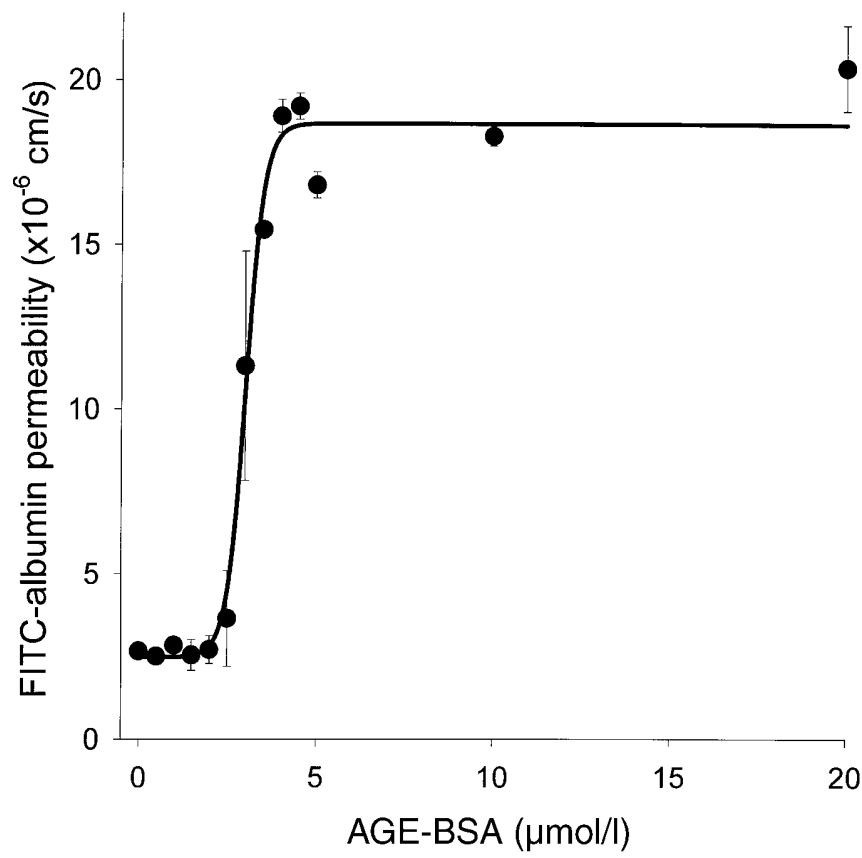

Fig.1. FITC-albumin permeability-response curves for a 48 -h incubation time. Filled circles $(\mathbf{O})$ are the mean values from 3-5 experiments in the region where permeability was changing from minimum to maximum and from $2-3$ experiments below and above this region. The curve through the data is a sigmoidal fit

tration producing a half-maximal permeability increase was about $3 \mu \mathrm{mol} / \mathrm{l}$. The data and curve fits for 12 and $24 \mathrm{~h}$ of incubation (not shown) are quite similar. Other experimental data (not shown) indicate that AGE-BSA doses of 3-3.5 $\mu \mathrm{mol} / 1$ produce permeability increases as early as with in $3-4 \mathrm{~h}$ of incubation. These results are similar to those reported previously [11], although their permeability results were for inulin, a much smaller solute.

Control experiments. Bovine serum albumin was incubated in phosphate buffer for $30 \mathrm{~d}$ in the absence of glucose, yielding non-glycated BSA (NG-BSA). We expected that this incubation mixture would produce no increases in permeability; however, NG-BSA stimulated the same increase in permeability as the AGEBSA $\left(15 \pm 0.4\right.$ and $16 \pm 0.4 \cdot 10^{-6} \mathrm{~cm} / \mathrm{sec}$, respectively). The kinetics of these changes (not shown) were also similar. Hence, it was either the incubation process at $37^{\circ} \mathrm{C}$, some non-protein component(s) of the buffer mixture or a degradation product of albumin formed during the incubation which produced the permeability increase. However, high glucose in the media could not have induced oxidative stress to some cells in culture [21] because there was no glucose in the NG-BSA mixture added to the cells.

Dialysis and filtration experiments. To identify the substance(s) responsible for the increase in perme- 
ability, we dialysed $3.5 \mu \mathrm{mol} / \mathrm{l}$ AGE-BSA mixture against $0.9 \%$ saline for $24 \mathrm{~h}$ and tested the ability of the retentate to increase permeability. The first dialysis was with a 6000 to $8000 \mathrm{M}_{\mathrm{r}}$ cutoff dialysis tubing. A 48-h incubation of the retentate on the cells produced no increase in permeability. Hence, the active agent in this AGE-BSA mixture has a molecular weight less than this cutoff value, possibly including protein fragments and buffer constituents. To further refine the MW range, we used dialysis tubing with a $500 \mathrm{M}_{\mathrm{r}}$ cutoff and again found no activity in the retentate. Hence, the active agent has a molecular weight less than approximately $500 \mathrm{M}_{\mathrm{r}}$ To ensure that some aspect of the dialysis procedure did not inactivate the active agent, we used a centrifugal concentrator from which we could measure the activities of both retentate and filtrate. Only the filtrate $\left(<5000 \mathrm{M}_{\mathrm{r}}\right)$ retained the ability to increase permeability. The most likely conclusion from these experiments was that some low molecular weight substance(s) in the buffer solution was the active agent(s).

Time-dose-response relations for phosphate mixture. We investigated the effect of the buffer alone. Apart from glucose, phosphate is the most abundant low molecular-weight component added to the buffer mixture. For each $1 \mu \mathrm{mol} / 1$ concentration of AGE-BSA added to the HEPES-EMEM cell incubation medi$\mathrm{um}$, there is $1.4 \mathrm{mmol} / \mathrm{l}$ of phosphate added. Hence, the amount of phosphate added with $2.5 \mu \mathrm{mol} / 1$ AGE-BSA was $3.5 \mathrm{mmol} / \mathrm{l}$, with $3 \mu \mathrm{mol} / \mathrm{l}$ AGE-BSA was $4.2 \mathrm{mmol} / \mathrm{l}$, etc. Because normal EMEM contains $1 \mathrm{mmol} / \mathrm{l}$ phosphate, then the totals would be $4.5 \mathrm{mmol} / \mathrm{l}, 5.2 \mathrm{mmol} / 1$, etc., comparable to phosphate concentrations commonly used in phosphate buffered saline. Permeability changes induced by phosphate buffer alone were essentially identical to those obtained with AGE-BSA solutions in phosphate buffer (Fig. 2). Data for incubation periods of 3 to $24 \mathrm{~h}$ with phosphate buffer (not shown) were similar to those for AGE-BSA in equivalent concentrations.

Metal-chelation experiments. It is possible that it was not phosphate, itself, but some impurity obtained with this chemical that stimulated the permeability increase. Probable candidates are traces of transition metal ions, such as copper and iron. To test for this possibility, various metal chelators were added to the cells along with the AGE-BSA mixture. Our data shows that chelator concentrations of about $0.5 \mathrm{mmol} / 1$, or higher, completely inhibited the permeability increase induced by a 48-h incubation of either the AGE-BSA in phosphate buffer or the phosphate buffer alone, indicating that it is one or more chelatable substances, which are the active components (Fig. 3).

We also used a chelating resin to remove divalent metals from the phosphate buffer (See Methods).

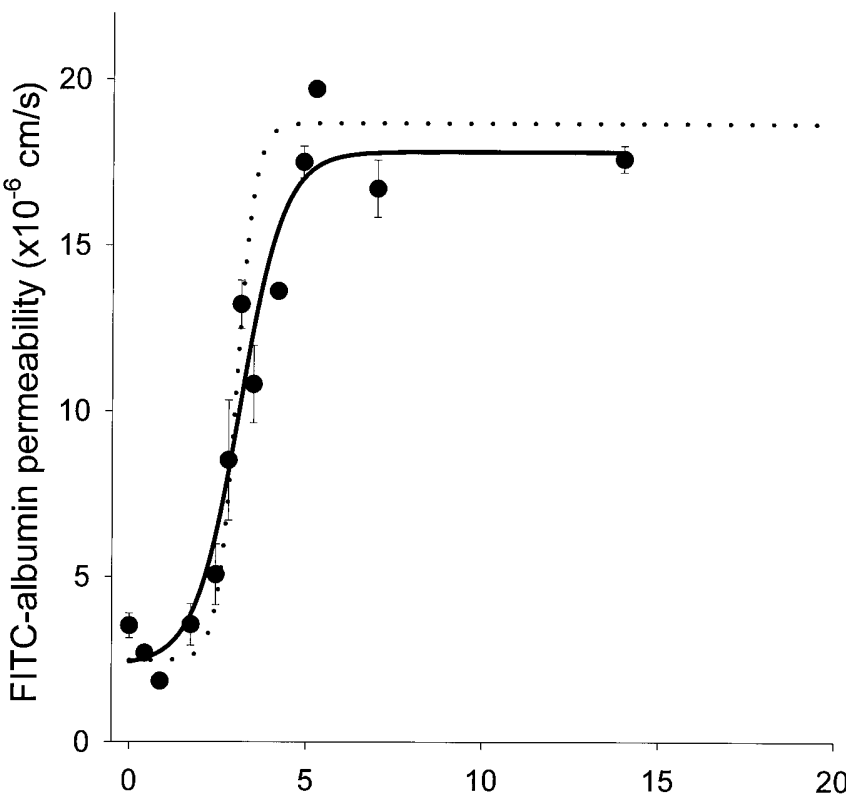

Added phosphate $(\mathrm{mmol} / \mathrm{l})$ or AGE-BSA $(\mu \mathrm{mol} / \mathrm{l})$

Fig. 2. Permeability-response curve to added phosphate buffer. The range of added phosphate corresponds to that in the AGE-BSA solution added in Figure 1. The characteristics of the sigmoidal curve $(-)$ fit to the data are quite similar to the dotted curve $(\cdots)$ shown for the AGE-BSA data of Fig. 1

The large increase in permeability induced by a 48-h incubation with the untreated phosphate buffer $(4.9 \mathrm{mmol} / \mathrm{l}$ added $)$, was totally inhibited $(17 \pm 0.5 \mathrm{re}-$ duced to $\left.3.2 \pm 0.6 \cdot 10^{-6} \mathrm{~cm} / \mathrm{sec}, p<0.001, n=5\right)$ by chelating the metal ions in the buffer before incubation on the cells.

Effect of serum. In our experimental system and in another study [11], the HEPES-EMEM incubated with the cells was serum free. Hence, the medium was devoid of substances normally present in serum that both bind metal ions and have antioxidant properties. We therefore assessed the ability of added serum to inhibit the permeability-increasing effects of the phosphate buffer. In a 48-h incubation, either 10 or $20 \%$ FBS added to the HEPES-EMEM totally blocked the ability of the phosphate buffer $(5.6 \mathrm{mmol} / \mathrm{l}$ added $)$ to increase permeability $(13 \pm 3$ reduced to $3.2 \pm 0.1$ or $4.4 \pm 0.3 \cdot 10^{-6} \mathrm{~cm} / \mathrm{sec}$, respectively, $p<0.05, n=3)$. Similar effects were observed using AGE-BSA (data not shown).

Effect of endothelial glutathione depletion. Buthionine sulfoximine (BSO), an agent which depletes intracellular glutathione (mainly GSH) [22], was used to test the hypothesis that lowering glutathione concentration would cause endothelial dysfunction, specifically a loss of barrier function. The permeability response to BSO incubated with the cells for $48 \mathrm{~h}$ is shown in Figure 4. As seen, 1-2 mmol/l BSO in- 


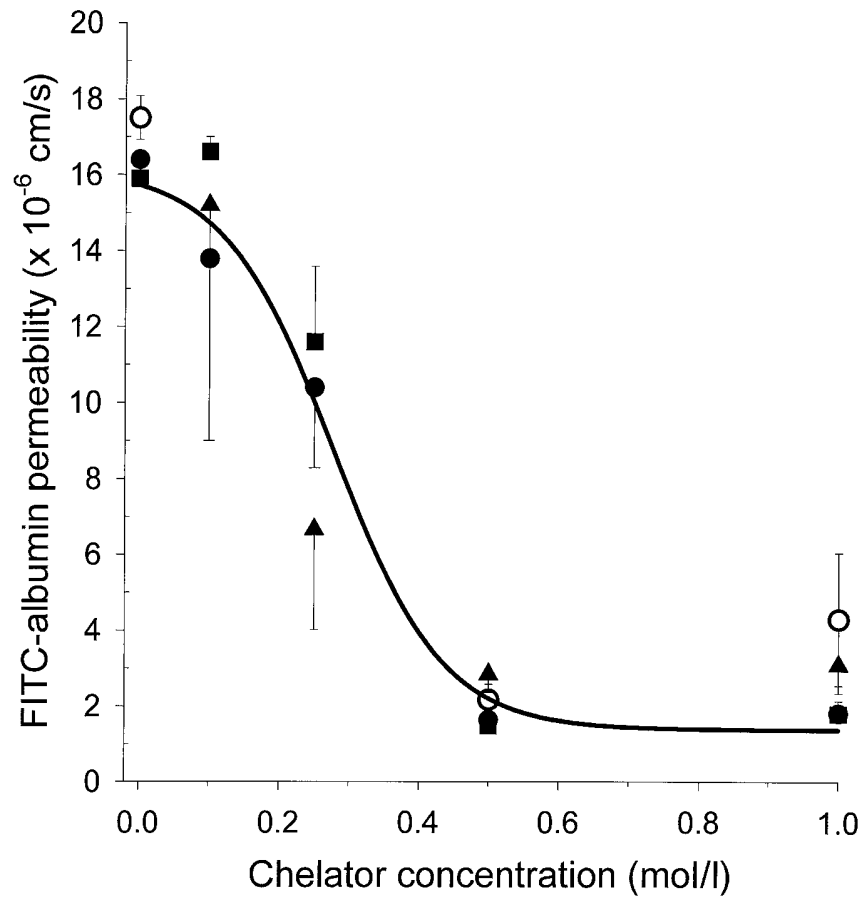

Fig.3. Effect of metal chelators on permeability increase induced by AGE-BSA or the equivalent added phosphate buffer after a 48-h incubation period. Each data point for EGTA ( $(\bullet)$, $(3.5 \mu \mathrm{mol} / 1 \mathrm{AGE}-\mathrm{BSA}+\mathrm{EGTA})$ is the mean of 2-6 experiments whereas there were 3 experiments using EDTA (ם), $(3.5 \mu \mathrm{mol} / 1 \mathrm{AGE}-\mathrm{BSA}+\mathrm{EDTA})$ and DTPA $(\boldsymbol{\Delta}),(3.5 \mu \mathrm{mol} / 1$ AGE-BSA + EDTA). Control permeability values were $1.82 \pm 0.16 \cdot 10^{-6} \mathrm{~cm} / \mathrm{s}$. All chelators at concentrations $\geq 0.5 \mathrm{mmol} / 1$ totally blocked the increase in permeability caused by the AGE-BSA. At these concentrations, EGTA also blocked the increase caused by the phosphate buffer (O), (4.9 mmol/l phosphate + EGTA)

creased permeability about three times the control, whereas $5 \mathrm{mmol} / \mathrm{l} \mathrm{BSO}$ produced a near-maximal permeability response.

Conversely, if the AGE-BSA or phosphate buffer solutions increase permeability by depleting endothelial GSH, then raising GSH concentration should inhibit this response. To test this hypothesis, we preincubated the cells with $N$-acetylcysteine (NAC, an intracellular GSH precursor) along with the AGEs or phosphate for $48 \mathrm{~h}$. NAC $(10 \mathrm{mmol} / \mathrm{l})$ totally blocked the increase caused by either the $3.5 \mu \mathrm{mol} / \mathrm{l}$ AGE-BSA $\left(16 \pm 0.4\right.$ reduced to $0.9 \pm 0.1 \cdot 10^{-6} \mathrm{~cm} /$ sec, $n=5)$ or $4.9 \mathrm{mmol} / 1$ phosphate buffer added $\left(16 \pm 1\right.$ to $\left.1.1 \pm 0.1 \cdot 10^{-6} \mathrm{~cm} / \mathrm{sec}, n=3\right)$.

Glutathione (GSH). To verify that lowering endothelial GSH concentration was consistent with an increase in permeability, we measured the changes in GSH induced by phosphate buffer and BSO for $48 \mathrm{~h}$ of incubation. Control glutathione concentrations were $27 \pm 4 \mathrm{nmol} / \mathrm{mg}$ protein. Incubation for $48 \mathrm{~h}$ in EMEM reduced glutathione to $9 \pm 1 \mathrm{nmol} / \mathrm{mg}$ protein $(n=9)$ probably due to the oxidant stress caused

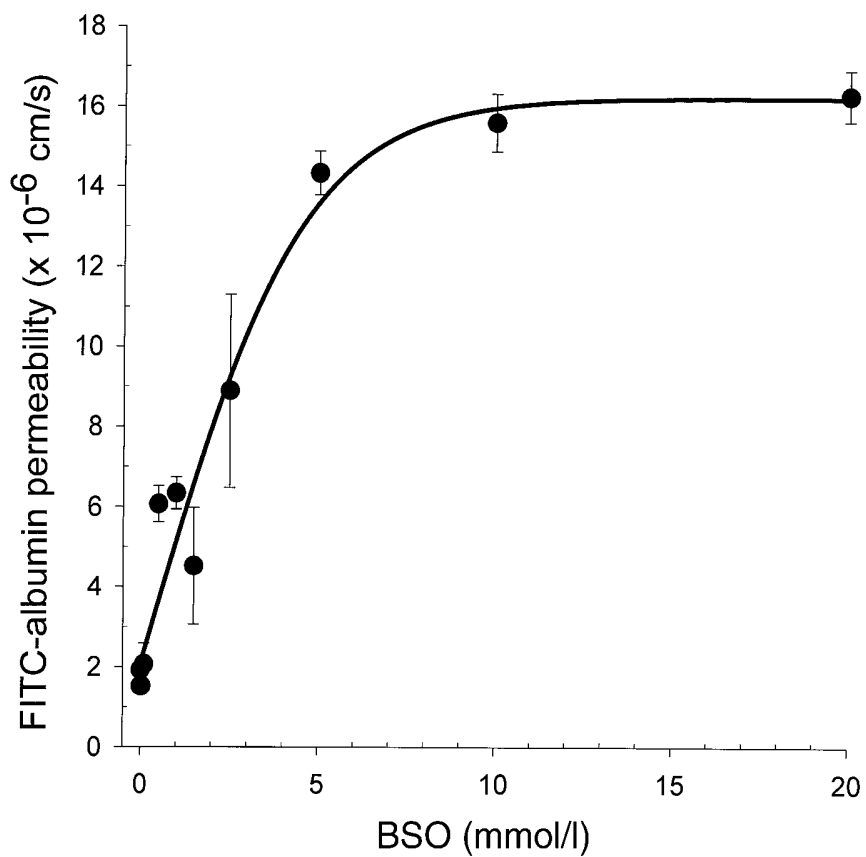

Fig.4. Permeability-response to buthionine sulfoximine (BSO), an agent which lowers intracellular glutathione (GSH). Each data point represents the mean of 2-6 experiments. BSO was added to the cells for a 48 -h incubation period

by the lack of antioxidants in the incubating media. Glutathione concentration was lowered further to $4.3 \pm 0.5 \mathrm{nmol} / \mathrm{mg}$ protein by $6.3 \mathrm{mmol} / 1$ phosphate and $2 \mathrm{mmol} / \mathrm{l} \mathrm{BSO}$ lowered this concentration even further, to $1.3 \pm 0.2 \mathrm{nmol} / \mathrm{mg}$ protein $(n=7)$. However, as found above, only the phosphate and BSO lowered permeability significantly, suggesting that there is some threshold concentration of glutathione below which permeability increases are induced.

NAC (10 mmol/l) totally inhibited the depletion of cellular GSH caused by the phosphate buffer solution. The glutathione concentration increased to $8.9 \pm 1.4 \mathrm{nmol} / \mathrm{mg}$ protein, which is near control values. Hence, these glutathione data are consistent with the hypothesized role of low GSH as an inducer of permeability changes.

Digital imaging immunofluorescence. To further investigate the mechanism of the permeability increase, we examined changes in endothelial cell stress fibres (F-actin, green), cell-to-cell adhesion ( $\alpha$-catenin, blue) and cell-to-matrix focal adhesions (paxillin, red) associated with an exposure to either AGEs or phosphate as seen in Figure 5. Panel (A) shows control cells with a uniform distribution of F-actin (arrow) and some randomly distributed focal paxillin staining (arrowhead) with distinct $\alpha$-catenin staining at the periphery of the cells (double arrow). The prominent features of the middle (B) and lower (C) panels are rounded up and contracted cells with huge paracellular holes (*). In these cells, the F-actin 

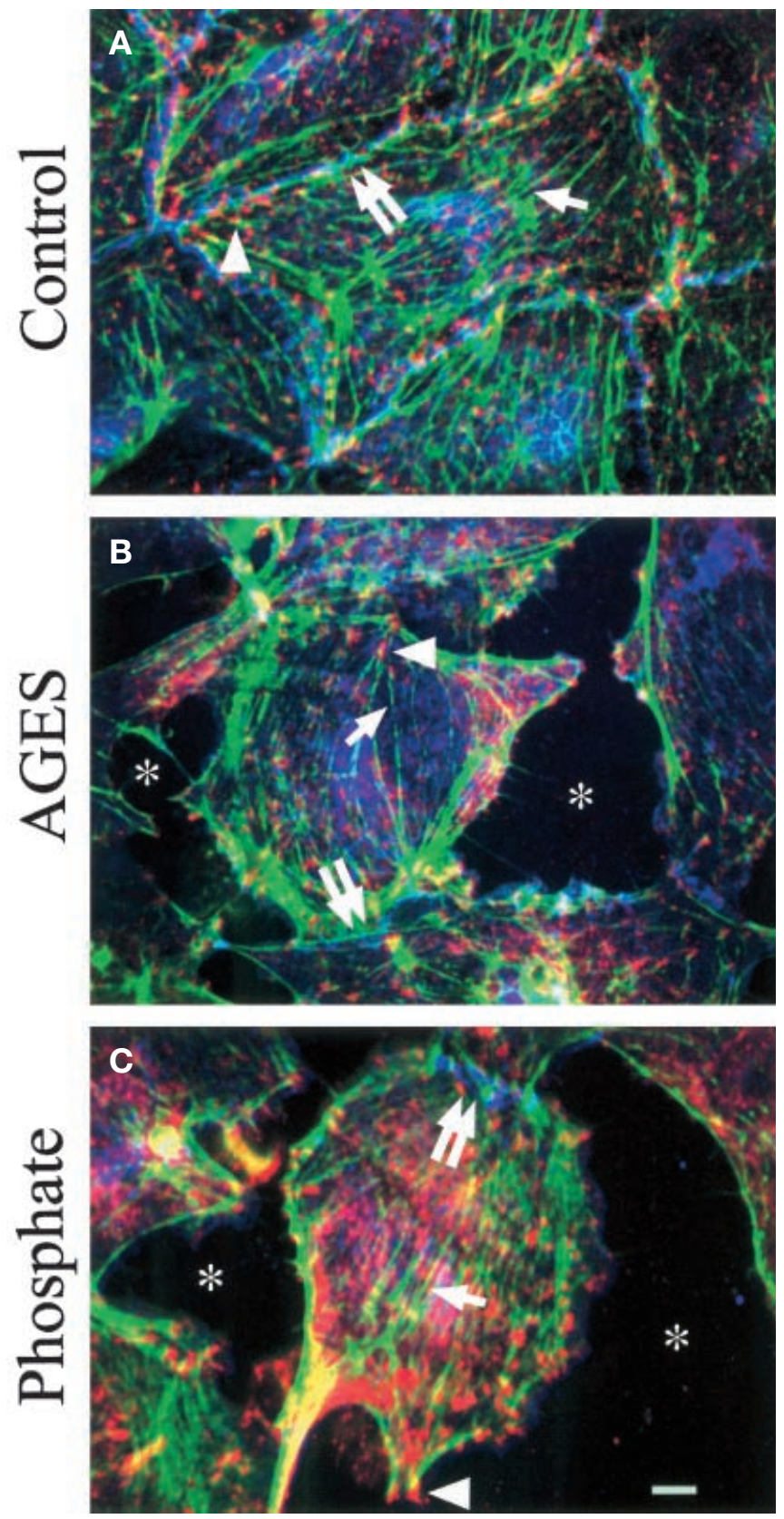

Fig.5. Morphological characteristics associated with a 48-h exposure of monolayers to $4.5 \mu \mathrm{mol} / \mathrm{l} \mathrm{AGEs}$ or $6.3 \mathrm{mmol} / \mathrm{l}$ added phosphate. Cells were triple labelled for F-actin (green), $\alpha$ catenin (blue) and paxillin (red). The upper panel (A) shows control cells with a uniform distribution of F-actin stress fibres $(\rightarrow)$ and some randomly distributed paxillin containing focal adhesions ( $)$ with distinct $\alpha$-catenin-containing cell-to-cell adhesions at the periphery of the cells $(\rightrightarrows)$. The prominent features of the middle $(\mathbf{B})$ and lower $(\mathbf{C})$ panels are rounded up and contracted cells with huge paracellular holes $(*)$. In these cells, the F-actin is distributed mainly in a dense peripheral band, $\alpha$-catenin is prominent only at the small region of cellto-cell contact and paxillin is concentrated at the ends of $\mathrm{F}$-actin stress fibres. Note in panels $(\mathbf{B})$ and $(\mathbf{C})$ the wisps of F-actin emanating from the cells, consistent with loss of attachment between cells. The Bar $=5 \mu$ is distributed in a dense peripheral band, $\alpha$-catenin is prominent only at the small region of cell-to-cell contact and paxillin is concentrated at the ends of F-actin stress fibres. Hence, both AGE-BSA and the phosphate buffer produce similar morphologic changes in these cells.

\section{Discussion}

Our initial goal was to identify specific AGEs involved in increasing the permeability of endothelial monolayers, with the expectation that these same AGEs would be involved in the development of vascular dysfunction in diabetes. Our unexpected finding was that all of the effects of AGE-BSA on the permeability of BPAEC monolayers could be attributed to metal ions in the buffer used to prepare the AGE-BSA. Similar results were obtained with several different preparations of AGE-BSA and phosphate buffers. In our studies, we were not able to duplicate the AGE-specific increase in endothelial barrier function reported previously [11]. However, it is possible that their result could have been caused by the same factors as in our study.

Unfortunately, there are no standardized methods of preparing AGE-proteins. In various studies [11, 23-26], AGE-BSA has been prepared by incubation of BSA for 4 to 8 weeks at $37^{\circ} \mathrm{C}$ or higher, in a phosphate buffer with a range of glucose $(50-500 \mathrm{mmol} / \mathrm{l})$ and phosphate (10-500 mmol/l) concentrations and then dialysed against PBS (10-20 $\mathrm{mmol} / \mathrm{l}$ phosphate). Hence, the final mixture probably contained at least a $10 \mathrm{mmol} / \mathrm{l}$ phosphate concentration and proportional amounts of metals, possibly including metal ions bound to AGE-proteins (see below). Dilution with culture medium would reduce these concentrations, but the final concentrations depend on the degree of dilution, which depends on the stock protein concentration, not specifically stated in most studies. Comparison between the various studies are further confounded by the possibility that, based on the conditions of their preparation, AGE-proteins could enhance metal-catalysed oxidation reactions [27] by binding and activating the metal ions [28]. Thus, in some experiments, protein-AGE-metal complexes could act as catalysts of oxidation reactions, inducing oxidative stress to plasma membrane lipids in endothelial cells, leading to an alteration in their barrier function.

The specific metal ion(s) mediating these permeability changes has not been identified. However, similar effects were observed with several different batches of phosphate buffer from different suppliers. Phosphate is a "mined" buffer, i.e. the product of open-pit mining operations. The metal-ion content of the buffers will vary with the supplier and site of production and it is likely that multiple ions could 
contribute additively or synergistically to the cytotoxicity of the buffer. We have found that addition of 100-500 nmol/l concentrations of $\mathrm{Cd}^{++}$and $\mathrm{Hg}^{++}$to metal-free buffers produce effects comparable to those of untreated phosphate. It is likely that some redox-active metal ions will induce oxidative stress by catalysing the production of ROS, whereas others could react directly with sulphhydryl groups of proteins and GSH, reducing cellular GSH and compromising antioxidant protection. In either case, the balance between pro-oxidant and anti-oxidant processes is disturbed, leading to cytotoxicity and resultant functional changes, including an altered endothelial permeability.

Our findings question the effects of AGE-proteins on permeability of endothelial monolayers in cellculture systems, which are often used as models for studies on vascular dysfunction in diabetes and other diseases. Regardless of the validity of earlier studies, however, our work points to the dangers associated with studies of cellular responses in serum-free media, particularly in phosphate buffer systems. Of note, the same caution applies to studies using carbonate-buffered systems because carbonate is also derived from mineral deposits and contains traces of iron, copper and other metal-ion contaminants which could induce oxidative stress in the absence of plasma proteins. Also, various batches of phosphate buffer could differ widely in their total and individual metal-ion content, precluding inter-laboratory replication of experimental results. Thus, it seems advisable to use Chelex-treated [27] buffers, whenever possible. We suggest that our observations regarding effects of contaminating metal ions and reproducibility of experiments could also apply to studies on induction of oxidative stress to cells grown in vitro in hyperglycaemic, protein-free media. In these systems, not only are cells deprived of endogenous antioxidants, but chelation of contaminating metal ions by plasma proteins is also precluded. Many of these studies, done in protein-free phosphate-buffered and bicarbonate-buffered media, even for short periods of time, could yield biological responses that are not likely to occur in vivo where concentrations of metalions and intracellular GSH concentrations are more tightly controlled.

Acknowledgements. We would like to thank J. Onorato for providing and characterizing some of the AGE-BSA used in this study. We also thank E. Johnson who carried out some of the studies with phosphate buffer and E. Endler and H. Curry for carrying out some of the preliminary studies with the AGE-BSA. This study was supported by an NIH Research Grant DK-19971 to J. W. Baynes and an American Diabetes Association Grant to M.B. Wolf.

\section{References}

1. Pinter GG, Lightman SL, Wilson PD, Yuen L, Bradbury MWB (1991) Albumin escape from microvessels in kidney, heart and skeletal muscle in experimental diabetes mellitus in the anesthetized rat. Exp Physiol 76: 899-904

2. Viberti GC (1983) Increased capillary permeability in diabetes mellitus and its relationship to microvascular angiopathy. Am J Med 75: 81-84

3. Parving HH (1976) Increased microvascular permeability to plasma proteins in short- and long-term juvenile diabetics. Diabetes 25[Suppl 2]: 884-889

4. Vlassara H (1994) Recent progress on the biologic and clinical significance of advanced glycosylation end products. J Lab Clin Med 124: 19-30

5. Baynes JW, Thorpe SR (1999) Role of oxidative stress in diabetic complications. A new perspective on an old paradigm. Diabetes 48: 1-9

6. Higashi T, Sano H, Saishoji T et al. (1997) The receptor for advanced glycation end products mediates the chemotaxis of rabbit smooth muscle cells. Diabetes 46: 463-472

7. Schmidt AM, Hori O, Brett J, Yan SD, Wautier J-L, Stern D (1994) Cellular receptors for advanced glycation end products: Implications for induction of oxidant stress and cellular dysfunction in the pathogenesis of vascular lesions. Arterioscler Thromb 14: 1521-1528

8. Vlassara H, Bucala R, Striker L (1994) Pathogenic effects of advanced glycosylation: biochemical, biologic, and clinical implications for diabetes and aging. Lab Invest 70: 138-151

9. Brownlee M (1994) Glycation and diabetic complications. Diabetes 43: 836-841

10. Bonnardel-Phu E, Wautier J-L, Schmidt AM, Avila C, Vicaut E (1999) Acute modulation of albumin microvascular leakage by advanced glycation end products in microcirculation of diabetic rats in vivo. Diabetes 48: 2052-2058

11. Esposito C, Gerlach H, Brett J, Stern D, Vlassara H (1989) Endothelial receptor-mediated binding of glucose-modified albumin is associated with increased monolayer permeability and modulation of cell surface coagulant properties. J Exp Med 170: 1387-1407

12. Kislinger T, Fu C, Huber B et al. (1999) $N^{e}$-(Carboxymeth$\mathrm{yl}$ )lysine adducts of proteins are ligands for receptor for advanced glycation end products that activate cell signaling pathways and modulate gene expression. J Biol Chem 274: 31740-31749

13. Van Reyk DM, Brown AJ, Jessup W, Dean RT (1995) Batch to batch variation of Chelex-100 confounds metalcatalysed oxidation. Leaching of inhibitory compounds from a batch of Chelex-100 and their removal by a prewashing procedure. Free Radical Res 23: 533-535

14. Buettner GR (1990) Use of ascorbate as a test for catalytic metals in simple buffers. In: Packer L, Glazer AN (eds) Oxygen Radicals in Biological Systems. Part B. Oxygen Radicals and Antioxidants. Academic Press, San Diego, p 125-127

15. Schaeffer RC Jr, Gong F, Bitrick MS Jr (1992) Restricted diffusion of macromolecules by endothelial monolayers and small-pore filters. Am J Physiol 263: L27-L36

16. Blakeslee D, Baines MG (1976) Immunofluorescence using dichlorotriazinylaminofluorescein (DTAF). I. Preparation and fractionation of labelled IgG. J Immunol Methods 13: $305-320$

17. Albeda SM, Sampson PM, Haselton FR et al. (1988) Permeability characteristics of cultured endothelial monolayers. Am J Physiol 64: 308-322 
18. Griffith OW (1980) Determination of glutathione and glutathione disulfide using glutathione reductase and 2-vinylpyridine. Anal Biochem 106: 207-212

19. Carbajal JM, Schaeffer RC Jr (1998) $\mathrm{H}_{2} \mathrm{O}_{2}$ and genistein differentially modulate protein tyrosine phosphorylation, endothelial morphology and monolayer barrier function. Biochem Biophys Res Commun 249: 461-466

20. Daniel WW (1987) Biostatistics: A Foundation for Analysis in the Health Sciences. Wiley, New York

21. Nishikawa T, Edelstein D, Du XL et al. (2000) Normalizing mitochondrial superoxide production blocks three pathways of hyperglycaemic damage. Nature 404: 787-790

22. Tsan M-F, Danis EH, Del Vecchio PJ, Rosano CL (1985) Enhancement of intracellular glutathione protects endothelial cells against oxidant damage. Biochem Biophys Res Commun 127: 270-276

23. Reddy S, Bichler J, Wells-Knecht KJ, Thorpe SR, Baynes JW (1995) $N^{e}$-(carboxymethyl)lysine is a dominant advanced glycosylation end-product (AGE) antigen in tissue proteins. Biochem J 34: 10872-10878

24. Schmidt AM, Hori O, Chen JX et al. (1995) Advanced glycation endproducts interacting with their endothelial re- ceptor induce expression of vascular cell adhesion molecule-1 (VCAM-1) in cultured human endothelial cells and mice: A potential mechanism for the accelerated vasculopathy of diabetes. J Clin Invest 96: 1395-1403

25. Schmidt AM, Vianna M, Gerlach M et al. (1992) Isolation and characterization of two binding proteins for advanced glycosylation end products from bovine lung which are present on the endothelial cell surface. J Biol Chem 267: 14987-14997

26. Bierhaus A, Chevion C, Chevion M et al. (1997) Advanced glycation end product-induced activation of NF-kappaB is suppressed by alpha-lipoic acid in cultured endothelial cells. Diabetes 46: 1481-1490

27. Qian M, Liu M, Eaton JW (1998) Transition metals bind to glycated proteins forming redox active "glychochelates": implications for the pathogenesis of certain diabetic complications. Biochem Biophys Res Commun 250: 385-389

28. Saxena AK, Saxena P, Wu X, Obrenovich M, Weiss MF, Monnier VM (1999) Protein aging by carboxymethylation of lysines generates sites for divalent metal and redox active copper binding: relevance to diseases of glcoxidative stress. Biochem Biophys Res Commun 260: 332-338 